\title{
A NOVEL USE OF CALCIUM ALUMINATE CEMENTS FOR RECYCLING WASTE FOUNDRY SAND (WFS)
}

Í. Navarro-Blasco, J.M. Fernández, A. Duran, R. Sirera, J.I. Álvarez*

Inorganic Materials \& Environment (MIMED), Department of Chemistry and Soil Sciences, School of Sciences, University of Navarra. Irunlarrea, 1. 31008 Pamplona, Spain

*Corresponding author:

Dr. José I. Alvarez

Inorganic Materials \& Environment (MIMED), Department of Chemistry and Soil Sciences, School of Sciences, University of Navarra. Irunlarrea, 1. 31008 Pamplona, Spain

Phone: +34948425600

Fax: +34948425740

E-mail: jalvarez@unav.es, $\underline{\text { mimed@unav.es }}$ 


\begin{abstract}
The recycling of WFS in calcium aluminate cement mortars at high level of replacement (50\%) was studied. Consistency and setting time were measured in fresh mortars. Two different curing conditions were used, the second one with the aim of enhancing the formation of stable cubic calcium aluminate hydrates. Compressive strength, pore size distribution and SEM examination were carried out to assess the effectiveness of CAC matrix in the recycling of WFS. The effect of the incorporation of a polymeric admixture - a chitosan derivative - was also explored. Leaching studies on hardened mortars of three target pollutants of the WFS (toxic metals $\mathrm{Pb}, \mathrm{Cr}$ and $\mathrm{Zn}$ ) were also done to evaluate their immobilization. By comparison with OPC mortars, the use of CAC showed several advantages, improving the compressive strength and the toxic metal retention.
\end{abstract}

Keywords: calcium aluminate cement; leaching; compressive strength; SEM; toxic metals; pore size distribution. 


\section{INTRODUCTION}

Foundry sand is a by-product of ferrous and nonferrous metal casting industries, in which sand is used as a molding material. When the sand can no longer be reused, it becomes a hazardous material according to European regulations as quoted by AlonsoSanturde et al. [1], since it can contain heavy metals and different pollutants [2-3]. The usual fate of this sand - several MT per year - is to be landfilled after a previous process of solidification/stabilization. Owing to high landfilling costs and environmental concerns, some researchers have reported other management alternatives for these polluted WFS, such as subbases, soils, ceramics, controlled-low-strength materials and concretes [4-8]. In these last two cases, WFS can be used to partially replace normal sand. Different issues related to this last point have been addressed: the effect of WFS on workability and compressive strengths, the freezing-thawing resistance of the concretes and the replacement levels [9-11]. In general, only low replacement levels (below 20\%) guarantee acceptable performance in the final concrete [5].

All the preexisting work shows two common characteristics: on the one hand, ordinary Portland cement (OPC) was used as the binding material; on the other hand, the recycling was focused on the preparation of concrete (with gravels, particles of aggregate showing diameter $>5 \mathrm{~mm}$ ) $[4,5,10,11]$. However, the present study aims to draw attention to: (i) the use of calcium aluminate cement (CAC) as an alternative binder to effectively solidify WFS, and (ii) the obtaining of mortars instead of concrete, with many different applications other than the structural concrete (unlike concrete, mortars are made of just fine sands). CAC is a kind of cement that is usually employed in the production of fire-resistant materials and also when concreting in temperatures below zero or when a fast increase in strength is required [12]. High early strength, chemical attack resistance and abrasion endurance, among other factors, have been 
reported for CAC-based materials [13], thus improving the encapsulation of certain toxic and radioactive wastes [14]. The clinkerization of a calcium aluminate cement yields anhydrous compounds, such as $\mathrm{CA}, \mathrm{CA}_{2}$ and $\mathrm{C}_{12} \mathrm{~A}_{7}$, whose reactivity increases as $\mathrm{CaO}$ content rises. The $\mathrm{CAC}$ reaction with water usually leads to the formation of metastable hexagonal phases, $\mathrm{CAH}_{10}$ and $\mathrm{C}_{2} \mathrm{AH}_{8}$ and amorphous aluminium hydroxide, which is followed by the formation of the stable cubic phases $\mathrm{C}_{3} \mathrm{AH}_{6}$ and $\mathrm{AH}_{3}$ at a higher temperature and in the presence of humidity. The latter usually involves a porosity increase - as a consequence of a contraction in the volume of solids - and a subsequent decrease in strength [15].

The use of CAC for WFS recycling and studies on the obtaining of mortars by sand replacement have so far not been reported. Therefore, this work focuses on the re-usage of WFS in CAC-based mortars with a high replacement level of the regular sand (50\%). The effect of the WFS on the CAC-based mortar properties (workability, setting time, compressive strength) are discussed, together with a complete microstructural characterization. A comparison with an OPC-based mortar is also presented. Additionally, a batch of fresh mixtures was modified upon the addition of a biodegradable polymer, carboxymethylchitosan $-\mathrm{CMCH}$ - which had successfully been used to improve the retention of toxic metals [16]. Finally, leaching studies were also conducted in order to ensure proper encapsulation of the toxic metals found in the WFS. 


\section{MATERIAL AND METHODS}

\subsection{Materials}

An iron-rich calcium aluminate cement (CAC) (provided by Ciments Molins) and an ordinary Portland cement (OPC) (CEM II 32,5 N, supplied by Portland S.A. Olazagutía, Spain) were used as binders for the preparation of the different batches of mortars. As aggregates, a regular sand of known grain size distribution (standardized siliceous aggregate, supplied by Eduardo Torroja Institute) and a waste foundry sand (supplied by Electroaceros, S.A., Pamplona, Spain) were used. The grain size distributions and chemical compositions of the sands were as described in Fig. 1 and Table 1, respectively. The amount of toxic metals was higher in WFS than in the regular sand (Table 2). For all the batches tested a constant water:cement ratio, 0.37:1 was used throughout.

One of the batches of samples was also modified by the incorporation of a polymeric admixture, carboxymethyl chitosan $(\mathrm{CMCH})$, in a 0.013 wt. \% with respect to the binder.

Table 3 shows the weight proportion of each one of the batches of samples. A total of 4 batches of samples was prepared: samples A made by just CAC with regular sand that acted as a control for CAC-bearing samples; samples B and C, obtained with CAC and aggregate made of $50 \%$ regular sand and $50 \%$ WFS. In samples $\mathrm{C}$, the $\mathrm{CMCH}$ is also present as admixture. Finally, samples D were made of OPC and sand (mixture of 50\% regular sand and 50\% WFS). Therefore, except for samples A, in all instances, regular sand was replaced by WFS for $50 \%$ of the weight. 


\subsection{Mortar preparation}

Dry raw materials, in the ratios reported in Table 3, were blended for 5 min with a BL8-Ca (Lleal, S.A.) mixer. Water was then added and mixed for $90 \mathrm{~s}$ at low speed in an Ibertest IB32-040E apparatus.

Cylindrical $40 \mathrm{~mm}$ height $\times 37 \mathrm{~mm}$ diameter specimens, prepared in triplicate, were cured under two different curing conditions:

- Curing condition 1: $20^{\circ} \mathrm{C}$ and 95\% $\mathrm{RH}$ [17] over the whole curing period.

- Curing condition 2: $60^{\circ} \mathrm{C}$ and $100 \% \mathrm{RH}$ [18] for 24 hours. Once this period was completed, temperature and $\mathrm{RH}$ were shifted towards $20^{\circ} \mathrm{C}$ and $95 \% \mathrm{RH}$.

Stable hydrated calcium aluminate phases were expected to develop easier under curing condition 2.

\subsection{Experimental methods}

For the fresh state properties of the mortars, different standardized tests were used to measure consistency, water retention capacity and setting time [19-21].

Once the samples had been cured for 28 days, compressive strength tests were carried out on a Proeti ETI 26.0052 at a loading rate of $50 \mathrm{~N} \mathrm{~s}^{-1}$ [22]. Pore size distributions (PSD) were obtained by mercury intrusion porosimetry (MIP) using a Micromeritics AutoPoreIV9500 with a pressure ranging between 0.0015 and $207 \mathrm{MPa}$. X-ray diffraction (XRD) was used to study the mineralogical composition in a Bruker D8Advance, with a $\mathrm{CuK}_{\alpha 1}$ radiation (step size $0.02^{\circ}(2 \theta)$ step time $1 \mathrm{~s}$; from $2^{\circ}$ to $50^{\circ}$ (20)). A semi quantitative approach based on the diffraction peaks intensities was 
applied with the aim of establishing the relative amount of the different crystalline phases [23].

The textural characteristics of the samples were observed, after coating with a palladium-gold film, by means of scanning electron microscopy (SEM), in a Zeiss microscope, coupled to a EDS detector.

In samples $\mathrm{B}, \mathrm{C}$ and $\mathrm{D}$, leaching tests of heavy metals were done. Similar cylindrical test pieces obtained as described above were placed in sealable $110 \mathrm{~mm} \times 110 \mathrm{~mm} \times 110$ $\mathrm{mm}$ methacrylate tanks. The determination of the leaching of inorganic components of mortars was carried out following the Tank Test [24]. This test requires monolithic hardened samples to be placed in $1 \mathrm{~L}$ of demineralized neutral $\mathrm{pH}$ water (leaching fluid). The leachate was replenished at specified times.

After the indicated period, all the leachate was drained off and filtered through a 0.45 $\mu \mathrm{m}$-pore size syringe filter (CHMLAB Group). Conductivity and $\mathrm{pH}$ measurements were carried out by means of a 4-Star benchtop $\mathrm{pH} /$ conductivimeter. A $10 \mathrm{~mL}$ aliquot of each sample was stored in sub-boiling $\mathrm{HNO}_{3}$ in order to quantify the leached metals. Eluates were collected at eight different times $(0.25,1,2.25,4,9,16,36$ and 64 days).

Quantification of metals was accomplished by AAS following the reported experimental conditions [16].

From the data collected, the measured cumulative leaching for each component was calculated using the procedure described in the norm for leaching of monolithic materials [24], recently used and reported elsewhere [25] : 
Leaching mechanism was determined from the slope of the linear regression analysis (log-log plots of cumulative leaching vs. time) through the eight data points, considered in different increments of time, as detailed in the EA NEN 7375:2004 norm [24].

\section{RESULTS AND DISCUSSION}

\subsection{Consistency and setting time of the fresh mortars}

Assays carried out in the CAC mortars loaded with WFS (samples B and C) showed (Table 4) that incorporation of WFS caused a decrease in the slump as a consequence of the different grain size distribution of the polluted sand, which shows a unimodal distribution centered around $0.25 \mathrm{~mm}$ with a smaller ratio of both the finest $(\leq 0.125$ $\mathrm{mm})$ and largest $(\geq 0.5 \mathrm{~mm})$ grains, as seen in Figure 1. The presence of an outstanding number of fine particles $(\leq 0.25 \mathrm{~mm})$ caused a decrease in the fluidity of the fresh mixtures, in line with previously reported data [26]. It must be considered that the fineness modulus of the WFS was 2.35, in the range of Medium Fineness modulus according to the EN 13139 norm [27]. However, the regular sand showed a higher fineness modulus (2.85), just in the limit of the Medium Fineness range. In the end, WFS meets the provisions of the standard on sand for masonry mortars, showing a particle size $\leq 2 \mathrm{~mm}[28]$

On the other hand, the replacement of standardized sand by WFS (samples B and C) induced a marked decrease in the setting time with respect to the regular sand CAC mortar (samples A). This is an especially favorable feature from a practical point of view when using these mortars to encapsulate the wasted sands. 
As for the effect caused by the presence of carboxymethyl chitosan $(\mathrm{CMCH})$ (mortars C), the most beneficial feature is the marked decrease in the setting time (42\%) that results in a speedier solidification/stabilization of the WFS (Table 4). This reduction in the setting time as a consequence of the action of the $\mathrm{CMCH}$ is in good agreement with the behavior also reported for OPC-based mortars [29].

\subsection{Mechanical, mineralogical and microstructural characterization of the 28-day cured mortars}

Hardened specimens after 28 days of curing were subjected to mechanical tests. Figure 2 shows the compressive strength values attained for the two curing conditions used.

It is clear that, after curing condition 1, compressive strength of both CAC and OPC mortars loaded with 50 wt.\% WFS (samples B, C and D) diminished with respect to the CAC made up with only regular sand (samples A). The different arrangement of the particle size distribution (PSD) when WFS was added explains these results. As a matter of fact, WFS showed a larger amount of fine particles $(\leq 0.25 \mathrm{~mm})$ and a smaller amount of bigger particles $(\geq 0.5 \mathrm{~mm})$ than those of the regular sand. Consequently, on the one hand the PSD packing resulted in a low degree of compactness and, on the other hand, the presence of a large population of small particles hindered a good adherence at the interface between the binding material and the larger aggregate particles. These two factors had a synergistic impact on the mechanical resistance, explaining its reduction. Nevertheless, it is also noteworthy that in samples under condition 1 of curing:

(i) CAC mortars with WFS (samples B and C) showed a much larger mechanical strength than the OPC mortars with WFS (sample D), and 
(ii) CAC specimens loaded with WFS (B and C) exhibited compressive strengths that could be classified as the most resistant M-20 mortars, according to the specifications for masonry mortars [30].

These facts prove CAC mortars to be an excellent end destination to conclude the usable life-cycle of foundry sands, presenting improvements with respect to the OPC mortars.

In CAC-based systems, it is well-known that, over the years, the conversion reaction from hexagonal metastable hydrates to the cubic stable ones causes a decrease in the mechanical resistance. Assays in a more drastic set of curing conditions (condition 2, $\left.60^{\circ} \mathrm{C} / 100 \% \mathrm{RH}\right)$ were used in order to estimate the long-term mechanical behavior of the CAC mortars. In fact, these curing conditions showed that conversion took place and cubic stable calcium aluminate hydrates were found by XRD, as depicted in Fig. 3. These stable hydrates are denser and, accordingly, render the cementitious matrix more porous and less resistant [31]. The forced conditions lead to a drop in the compressive strength that is expected to represent the maximum compressive strength loss over the years. In spite of this, the strength values measured for WFS-loaded CAC (B and C) fulfilled the strength requirements of the specifications for mortars for masonry (all CAC mortars subjected to curing condition 2 were M-10 mortars) and can be used for many different applications [30]. Simultaneously, the measured strengths remained well above the limits for landfilling [32].

XRD analysis led to the characterization of the chemical forms of the calcium aluminates present in samples B and C. Owing to the complexity of the CAC matrices, a semi-quantitative approach, based on the intensities of the diffraction peaks, was used to assess the presence of the phases and their relative amount (Fig. 3). 
Monocalcium aluminate, $\mathrm{CA}\left(\mathrm{CaAl}_{2} \mathrm{O}_{4}\right.$, main peaks: $\left.30.1^{\circ}, 19^{\circ} 2 \theta\right)$, appeared as the main anhydrous compound. This phase is predominantly formed after the clinkerization during the $\mathrm{CAC}$ production. Also metastable hydrates $\left(\mathrm{CAH}_{10}\right.$ peaks: $12.4^{\circ}, 25.06^{\circ}$, 27.3 $2 \theta$ and $\mathrm{C}_{2} \mathrm{AH}_{8}$ peak: $18^{\circ} 2 \theta$ ) and, in some samples, cubic stable compounds $\left(\mathrm{C}_{3} \mathrm{AH}_{6}\right.$, hydrogarnet, peaks: $17.26^{\circ}, 31.8^{\circ}, 33^{\circ}, 44.46^{\circ} 2 \theta$ and $\mathrm{AH}_{3}$, gibbsite, peaks: $18.33^{\circ}, 20.3^{\circ}, 36.6^{\circ} 2 \theta$ ) were identified (Figure 3). Chitosan-free specimens (sample B) cured under condition 1 showed mainly anhydrous and metastable compounds. After performing curing condition 2, these samples allowed us to observe cubic stable hydrated phases. The presence of the $\mathrm{CMCH}$ polymer (sample $\mathrm{C}$ ) enhanced the formation of the stable compounds, even under curing condition 1.

Pore size distribution assessment carried out by MIP showed, in CAC-mortars, different pore size distribution patterns as a function of the prevailing presence of either metastable or stable calcium aluminate compounds. The main presence of metastable compounds $\left(\mathrm{CAH}_{10}\right.$ and $\left.\mathrm{C}_{2} \mathrm{AH}_{8}\right)$ led to a unimodal pore size distribution, with pores of small diameter and main pore diameter at ca. $0.1 \mu \mathrm{m}$. This fact can be observed in the pore size distribution of samples A and B, after curing condition 1 (Fig. 4 a and b).

However, when conversion reaction took place (curing condition 2), the prevailing amount of the denser stable cubic calcium aluminate hydrates caused a porosity increase, with a shift of the main pore diameter towards higher diameters (ca. $1 \mu \mathrm{m}$ ), that justified the compressive strength drop (see the pore size distributions of samples A and $\mathrm{B}$ after condition 2 of curing, Fig. $4 \mathrm{a}$ and b).

MIP of CMCH-modified mortars (samples C) confirmed the XRD results, thus proving that the addition of the chitosan derivative as admixture enhanced the formation of stable calcium aluminate hydrates. In fact, the pore size distribution of samples $\mathrm{C}$ 
depicted the pattern of stable compounds, even after condition 1 of curing, with main pore diameter at ca. $1 \mu \mathrm{m}$ and reduced porosity below $0.1 \mu \mathrm{m}$. Fig. $4 \mathrm{c}$ shows the pore size distributions of samples $\mathrm{C}$, after the two curing conditions, yielding similar curves.

The replacement of the regular sand by WFS caused an increase in the large porosity (pores above $1 \mu \mathrm{m}$ ), owing to the aforementioned poor degree of the packing of the aggregate particles when WFS was present.

Microstructural examination of the samples by SEM showed that the sand particles of the WFS were well embedded in the CAC-cementitious matrix. Micrographs of samples B, under condition 1 of curing, depicted some areas showing a compact matrix, with gelified metastable hydrates (Fig. 5a). Sometimes cracks also were identified over the surface of the sample (Fig. 5b and c). At higher magnification, an ill-defined structure of hydrates could be observed, with some rods and plate-like crystals (Fig. 5d). SEM examination confirmed that these samples are of overall reduced porosity, as discussed in the MIP results.

For these samples B, cured under condition 2, a larger ratio of porosity and a pore size increase was observed as a consequence of the conversion into stable hydrates, as seen in the micrographs at low magnification (Fig. 6a). At higher magnification, the gel structure appeared to be less compact than the corresponding sample under condition 1 of curing (Fig. 6b). Some areas of these samples showed tabular gibbsite crystals together with some needle-like stable hydrates and certain hexagonal plate-like metastable hydrates that were also identified by $\mathrm{XRD}$ as $\mathrm{C}_{2} \mathrm{AH}_{8}$ compounds (Fig. 6c). A detail of tabular agglomeration of stable hydrates is depicted in Fig. 6d. In Fig. 6e, spherical agglomerates of $\mathrm{AH}_{3}$ of ca. $1 \mu \mathrm{m}$ within $\mathrm{AH}_{3}$ gel could be neatly distinguished 
[33], whereas in Fig. 6f, $\mathrm{C}_{3} \mathrm{AH}_{6}$ prismatic and tabular clusters of crystals of stable hydrates were seen.

The incorporation of the chitosan derivative (samples $\mathrm{C}$ ), after condition 1 of curing, gave rise to a less homogeneous matrix when compared to the chitosan-free samples $\mathrm{B}$. MIP results, above discussed, indicated larger porosity and bigger pore size for these samples, as a result of the conversion into stable hydrates that was enhanced by the polymeric admixture. Some pores and a lower degree of homogeneity in the matrix could be observed in Fig. 7a. An ill-defined structure, poorly compacted, with some quasi spherical $\mathrm{AH}_{3}$ crystals was seen in Fig. 7b. XRD results suggested the formation of stable cubic hydrates in these samples: this fact was confirmed by the presence of cubic and prismatic $\mathrm{C}_{3} \mathrm{AH}_{6}$ compounds, together with clusters of spherical $\mathrm{AH}_{3}$ crystals in $\mathrm{AH}_{3}$ gel matrix, as shown in Figs. 7c-f. In Fig. 7d and Fig. 7e, also hexagonallyshaped pinacoids related to the remaining presence of $\mathrm{C}_{2} \mathrm{AH}_{8}$ could be identified. Finally, Fig. $7 \mathrm{f}$ depicted also very thin sheets of stable hydrates.

Chitosan-bearing samples $\mathrm{C}$ after curing condition 2 presented similar microstructural features to samples subjected to curing condition 1, in good agreement with the MIP studies. Micrographs present a porous matrix accompanied by a low degree of compactness (Fig. 8 a-c), with some cracks on the surface of the gel compounds. Besides a poorly crystallized matrix, some cubic $\mathrm{C}_{3} \mathrm{AH}_{6}$ crystals could also be observed (Fig. 8d). Sometimes the hydrates showed a foil-like morphology, as depicted in Fig. 8e and detailed at higher magnification in Fig. 8f.

When the binder was OPC (samples D), under curing condition 1, the matrix showed reduced porosity (Fig. 9a and b). In some areas, fibrous C-S-H compounds and needles of ettringite were observed (Fig. 9c and d). Small spherical particles, probably fly ashes 
belonging to the OPC cement added during the cement production, could be identified (Fig. 9e). The curing under condition 2 for OPC-based mortars yielded an irregular matrix comprising some well-crystallized areas as well as other ill-defined structures (Fig. 9f).

To summarize, from a mechanical and microstructural point of view, the high level of replacement of regular sand by WFS in calcium aluminate cement matrices showed certain advantages in comparison with the same level of replacement in ordinary Portland cement systems. Although the addition of a polymeric chitosan derivative $\mathrm{CMCH}-$ as admixture in low amounts provoked a slight compressive strength reduction after condition 1 of curing, the presence of this admixture guaranteed that stable phases were achieved in short periods of curing at low temperatures without risk of later conversion and subsequent drop in mechanical resistance of the CAC mortar at longer periods of time. Additionally, the $\mathrm{CMCH}$ incorporation, at such a small percentage as $0.013 \%$, to CAC mortars loaded with WFS conferred a plus that ensures the quick stabilization of the wasted sand within the mortar owing to the setting time reduction. Under condition 1, these CAC mortars with high replacement level of WFS (samples B and C) showed a compressive strength that, while inferior to the samples A (only regular sand), was above the strength for a M-20 masonry mortar [30]. On the other hand, the incorporation of $50 \mathrm{wt} \%$ WFS into OPC (samples D) resulted in a weaker structure with a much more reduced compressive strength (just a M-10 mortar). This kind of CAC-based mortars could be useful for the obtaining of technical refractory mortars, quick bricklaying, refractory brick joining or corrosion resistant mortars. 


\subsection{Leaching tests}

Given that WFS appeared to be polluted by different heavy metals, three of them $(\mathrm{Pb}$, $\mathrm{Zn}$ and $\mathrm{Cr}$ ) were used as targets to monitor the retaining capacity of the mortars assessed. The selection was done on the basis of their relevance as toxic metals and their pernicious influence on the physical properties of mortars. Figure 10 depicts the comparative percentages of metals retained-released from the WFS when incorporated into mortars (samples $\mathrm{B}, \mathrm{C}$ and $\mathrm{D}$ ). $\mathrm{Pb}$ was seen to be fully retained by all the three batches of mortars, while $\mathrm{Cr}$ and $\mathrm{Zn}$ underwent a certain release from all three matrices (although in relatively small quantities). Nevertheless, maximum retentions for the metals were always achieved for the CAC mortars that had been modified by the addition of the chitosan derivative (samples C), whereas OPC mortars (samples D) showed the worst retention capacity in all instances. This circumstance supports the addition of $\mathrm{CMCH}$ as an effective retaining agent for heavy metals useful to stabilize/immobilize them into cement mortars, as previously described [16].

Conductivity measurements in Fig. 11 carried out in the eluates over time showed parallel patterns for the three assayed specimen types (samples B, C and D), in which the maximum conductivity is always obtained for the leachates of the OPC mortars (samples D). This fact is in good agreement with the highest portion of metals being released from that kind of mortar. Mechanistic approaches on the leaching process were based on the slopes of the log-log plots of derived cumulative leaching vs. time for different time increments, according to the norm [24]. The criteria reported for the interpretation were: when slopes were below 0.35, a surface wash-off (in the case of increment $1-4$ from 0.25 to 4 days) or depletions (for all the rest of time increments) prevailed; if gradient was between 0.35 and 0.65 the proposed mechanism was diffusion (for all the studied time intervals), whereas values higher than 0.65 indicated delayed 
diffusion (interval from 0.25 to 4 days) or dissolution (for all the rest of time increments). Table 5 displays the slopes calculated and associated standard deviations for the leaching of $\mathrm{Al}$ and $\mathrm{Fe}$ as tracers of the stability of the CAC matrix as well as of the toxic metals $\mathrm{Cr}$ and $\mathrm{Zn}$, found in WFS. When attention was focused on the leaching behavior of $\mathrm{Al}$, it was seen that in the long-term (time increment 5-8: 9-64 days) OPC mortars (samples D) yielded a larger slope for the release of Al than CAC mortars (samples B and C). In this case, while a depletion model was assigned to the Al within the CAC mortars, a diffusion pattern was ascribed to the OPC mortars (samples D). This experimental fact supports the comparatively long-term stability of CAC matrix with respect to the OPC mortars and agreed well with the higher conductivities observed for the OPC mortars. As for Fe, in the global increment (1-36 days), this stability trend could also be observed. In spite of the fact that the CAC matrix presented a larger amount of $\mathrm{Fe}$ in its composition, the leaching was diffusion-controlled unlike the OPC mortars (samples D) in which the leaching mechanism was governed by dissolution.

The mechanistic studies for $\mathrm{Zn}$ and $\mathrm{Cr}$ ( $\mathrm{Pb}$ not considered since it was completely retained) were hampered by their low concentrations in the leachates owing to the strong retention of these metals within the cementitious matrices. Data in Table 5 suggest that $\mathrm{Zn}$, in general, suffered a diffusion-controlled leaching. However, as for $\mathrm{Cr}$, depending on the curing condition, either a global wash-off or dissolution patterns were followed for CAC mortars, whereas a dissolution mechanism was the dominant pathway in the case of OPC mortars (samples D). 


\section{CONCLUSIONS}

Calcium aluminate cement has been proved to be a suitable matrix to prepare mortars for recycling of waste foundry sand in high level of replacement. As compared to ordinary Portland cement, parameters such as compressive strength and heavy metal retention were markedly improved when CAC was used as binding matrix. In all cases the minimum strength requirements for landfilling (1 MPa) were well complied with. All the tested CAC mortars were classified at least as M-10, taking into account the specifications for masonry mortars (all the tested mortars surpassed the compressive strength value of $10 \mathrm{MPa}$ ). Among toxic metals present as pollutants in WFS, $\mathrm{Cr}$ and $\mathrm{Zn}$ were seen to be better immobilized in the CAC mortars.

Both the compressive strength and toxic metal retention ability of the CAC mortars remained within acceptable ranges after the two test curing conditions followed in this study. The second condition $\left(60^{\circ} \mathrm{C} / 100 \% \mathrm{RH}\right)$ induced the formation of cubic stable hydrates, as proved by XRD and SEM examination. In these samples, porosity increased with a subsequent strength drop, which never fell below $12 \mathrm{MPa}$.

Several advantages were drawn from the incorporation of a polymeric chitosan derivative, carboxymethyl chitosan: (i) setting time reduction, with an ensuing enhancement of the WFS' pollutants retention; (ii) acceleration of stable hydrates formation even under curing condition $1\left(20^{\circ} \mathrm{C} / 95 \% \mathrm{RH}\right)$, while keeping reasonable mechanical resistance; and (iii) better toxic metal solidification/stabilization, especially for $\mathrm{Zn}$ and $\mathrm{Cr}$.

This work explores a novel and promising alternative that consists of using CAC as a valuable binding matrix to recycle WFS and other polluted materials. The final purpose of these materials could be to be landfilled or to use them as masonry mortars. 


\section{Acknowledgments}

The authors want to thank: Ciments Molins and Electroaceros, S.A.for the material supplied; Dr. M. Lasheras-Zubiate (FIDENA) for her assistance in the SEM analysis. Some of the experimental measurements were performed by Í. Gil as his B.Sc. final degree project. This work was funded by FUNA (Fundación Universitaria de Navarra) under project number FUNA2012-15108172.

\section{References}

[1] Alonso-Santurde R, Coz A, Viguri JR, Andrés A. Recycling of foundry byproducts in the ceramic industry: Green and core sand in clay bricks. Constr Build Mater 2012;27(1):97-106

[2] Siddique R, Kaur G, Rajor A. Waste foundry sand and its leachate characteristics. Resour Conserv Recycl 2010;54(12):1027-36

[3] Dungan RS, Dees NH. The characterization of total and leachable metals in foundry molding sands. J Environ Manage 2009;90(1):539-48

[4] Siddique R, Aggarwal Y, Aggarwal P, Kadri E-H, Bennacer R. Strength, durability, and micro-structural properties of concrete made with used-foundry sand (UFS). Constr Build Mater 2011;25(4):1916-25

[5] Basar HM, Aksoy ND. The effect of waste foundry sand (WFS) as partial replacement of sand on the mechanical, leaching and micro-structural characteristics of ready-mixed concrete. Constr Build Mater 2012;35:508-15

[6] Miguel RE, Ippolito JA, Leytem AB, Porta AA, Noriega RBB, Dungan RS. Analysis of total metals in waste molding and core sands from ferrous and nonferrous foundries. J Environ Manage 2012;110:77-81 
[7] Carnin RLP, Folgueras MV, Luvizão RR, Correia SL, da Cunha CJ, Dungan RS. Use of an integrated approach to characterize the physicochemical properties of foundry green sands. Thermochim Acta 2012;543:150-5

[8] Siddique R, Singh G. Utilization of waste foundry sand (WFS) in concrete manufacturing. Resour Conserv Recycl 2011;55(11):885-92

[9] Uwe Lahl U. Recycling of waste foundry sands. Sci Total Environ $1992 ; 114: 185-93$

[10] Singh G, Siddique R. Abrasion resistance and strength properties of concrete containing waste foundry sand (WFS). Constr Build Mater 2012;28(1):421-6

[11] Siddique R, de Schutter G, Noumowe A. Effect of used-foundry sand on the mechanical properties of concrete. Constr Build Mater 2009;23(2):976-80

[12] Juenger MCG, Winnefeld F, Provis JL, Ideker JH. Advances in alternative cementitious binders. Cem Concr Res 2011;41:1232-43

[13] Ukrainczyk N, Vrbos N, Šipušić J, Influence of metal chloride salts on calcium aluminate cement hydration. Adv Cem Res 2012;24:249-62

[14] Hidalgo A, Petit S, Garcia JL, Alonso C, Andrade C. Microstructure of the system calcium aluminate cement-silica fume: application in waste immobilization. In: Xu R, Gao Z, Chen J, Yan W, editors. From zeolites to porous MOF materials, Amsterdam: Elsevier; 2007, p. 1617-28.

[15] Luz AP, Pandolfelli VC. Halting the calcium aluminate cement hydration process. Ceram Int 2011;37:3789-93

[16] Lasheras-Zubiate M, Navarro-Blasco Í, Álvarez JI, Fernández JM. Interaction of carboxymethylchitosan and heavy metals in cement media. J Hazard Mater $2011 ; 194: 223-31$ 
[17] Matusinović T, Kurajica S, Šipušić J. The correlation between compressive strength and ultrasonic parameters of calcium aluminate cement materials. Cem Concr Res 2004;34:1451-7

[18] Sakai E, Sugiyama T, Saito T, Daimon M. Mechanical properties and microstructures of calcium aluminate based ultra-high strength cement. Cem Concr Res 2010;40:966-70

[19] EN 1015-3,2000: Methods of Test for Mortar for Masonry. Part 3: Determination of Consistence of Fresh Mortar (by Flow Table)

[20] UNE 83816,1993: Test Methods. Mortars. Fresh Mortars. Determination of Water Retentivity.

[21] EN 1015-9,2000: Methods of Test for Mortar for Masonry. Part 9: Determination of Workable Life and Correction Time of Fresh Mortar.

[22] EN 1015-11,2000: Methods of Test for Mortar for Masonry. Part 11: Determination of Flexural and Compressive Strength of Hardened Mortar.

[23] Gosselin C, Gallucci E, Scrivener K. Influence of self heating and $\mathrm{Li}_{2} \mathrm{SO}_{4}$ addition on the microstructural development of calcium aluminate cement. Cem Concr Res 2010;40:1555-70

[24] EA NEN 7375,2004: Leaching Characteristics of Moulded or Monolithic Building and Waste Materials, Determination of Leaching of Inorganic Components with the Diffusion Test.

[25] Lasheras-Zubiate M, Navarro-Blasco Í, Fernández JM, Álvarez JI. Encapsulation, solid-phase identification and leaching of toxic metals in cement systems modified by natural biodegradable polymers. J Hazard Mater 2012;233$234: 7-17$ 
[26] Guney Y, Sari YD, Yalcin M, Tuncan A, Donmez S. Re-usage of waste foundry sand in high-strength concrete. Waste Manage 2010;30(8-9):1705-13

[27] EN 13139, 2003/AC, 2004: Aggregates for Mortars.

[28] EN 1015-1,1999/A1,2007: Methods of Test for Mortar for Masonry - Part 1: Determination of Particle Size Distribution (by Sieve Analysis).

[29] Lasheras-Zubiate M, Navarro-Blasco Í, Fernández JM, Álvarez JI. Effect of the addition of chitosan ethers on the fresh state properties of cement mortars. Cem Concr Compos 2012;34(8):964-73

[30] EN 998-2, 2012: Specification for Mortar for Masonry - Part 2: Masonry Mortar

[31] Pacewska B, Wilinska I, Nowacka M. Studies on the influence of different fly ashes and Portland cement on early hydration of calcium aluminate cement. J Therm Anal Calorim 2011;106:859-68

[32] Dutch Soil Quality Regulation 2006.

[33] Rivas Mercury JM, De Aza AH, Turrillas X, Pena P. Hidratación de los cementos de aluminato de calcio. Parte II: Efecto de las adiciones de sílice y alúmina. Bol Soc Esp Ceram Vidr 2003;42:361-8. 
Table 1. Chemical composition of major components present in the regular and waste foundry sands.

\begin{tabular}{lcccccccccc}
\hline Constituent (\%) & $\mathrm{SiO}_{2}$ & $\mathrm{Al}_{2} \mathrm{O}_{3}$ & $\mathrm{TiO}_{2}$ & $\mathrm{CaO}$ & $\mathbf{M g O}$ & $\mathrm{Fe}_{2} \mathrm{O}_{3}$ & $\mathrm{Na}_{2} \mathrm{O}$ & $\mathrm{K}_{2} \mathrm{O}$ & $\mathrm{Cr}_{2} \mathrm{O}_{3}$ & $\mathrm{MnO}$ \\
\hline Regular sand & $93.4 \pm 2.1$ & $0.8 \pm 0.4$ & $0.73 \pm 0.01$ & $0.04 \pm 0.03$ & $0.04 \pm 0.03$ & $0.06 \pm 0.01$ & $0.22 \pm 0.01$ & $0.43 \pm 0.03$ & $0.001 \pm 0.001$ & $<\mathrm{LD}$ \\
Waste foundry sand & $88.5 \pm 1.0$ & $2.7 \pm 0.3$ & $0.61 \pm 0.02$ & $0.16 \pm 0.06$ & $0.19 \pm 0.04$ & $1.33 \pm 0.02$ & $0.46 \pm 0.06$ & $0.77 \pm 0.07$ & $0.045 \pm 0.002$ & $0.014 \pm 0.007$ \\
\hline
\end{tabular}

Table 2. Chemical composition reflecting the minor elements present in the tested sands.

\begin{tabular}{lccccc}
\hline Constituent $(\boldsymbol{m g} / \mathbf{k g})$ & $\boldsymbol{Z n}$ & $\boldsymbol{C u}$ & $\boldsymbol{P b}$ & $\boldsymbol{N i}$ & $\boldsymbol{C d}$ \\
\hline Regular sand & $<\mathrm{LD}$ & $4.0 \pm 0.9$ & $4.7 \pm 0.8$ & $2.4 \pm 0.3$ & $<\mathrm{LD}$ \\
Waste foundry sand & $42.9 \pm 1.6$ & $18.3 \pm 6.5$ & $13.2 \pm 2.0$ & $4.3 \pm 0.7$ & $0.04 \pm 0.01$ \\
\hline
\end{tabular}

Table 3. Weight composition (g) of every batch of mortars.

\begin{tabular}{ccccccc}
\hline $\begin{array}{c}\text { Batches of } \\
\text { samples }\end{array}$ & CAC & OPC & $\begin{array}{c}\text { Regular } \\
\text { sand }\end{array}$ & WFS & $\begin{array}{c}\text { Mixing } \\
\text { water }\end{array}$ & $\begin{array}{c}\text { Admixture } \\
\text { (CMCH) }\end{array}$ \\
\hline A & 390 & - & 610 & - & 144.3 & - \\
B & 390 & - & 305 & 305 & 144.3 & - \\
C & 390 & - & 305 & 305 & 144.3 & 0.05 \\
D & - & 390 & 305 & 305 & 144.3 & - \\
\hline
\end{tabular}

Table 4. Fresh state properties of CAC-based mortars (Samples A-C) and OPC mortars (Sample D).

\begin{tabular}{lcccc}
\hline \multicolumn{1}{c}{ Parameter } & Sample A & Sample B & Sample C & Sample D \\
\hline Slump (mm) & 173 & 114 & 118 & 144 \\
Water retention (\%) & 92.5 & 98.0 & 93.5 & 94.8 \\
Setting time (min) & 178 & 108 & 63 & 110 \\
\hline
\end{tabular}


Table 5. Calculated slopes and associated standard deviations of the log-log plots of derived cumulative leaching vs. time for different time increments.

\begin{tabular}{|c|c|c|c|c|c|c|}
\hline \multicolumn{7}{|c|}{$A l$} \\
\hline \multirow{2}{*}{ Step ${ }^{a}$} & \multicolumn{2}{|c|}{ Sample B } & \multicolumn{2}{|c|}{ Sample C } & \multicolumn{2}{|c|}{ Sample D } \\
\hline & Condition 1 & Condition 2 & Condition 1 & Condition 2 & Condition 1 & Condition 2 \\
\hline Increment 1-4 & $1.123 \pm 0.039$ & $1.151 \pm 0.037$ & $1.659 \pm 0.065$ & $1.556 \pm 0.079$ & $0.793 \pm 0.291$ & $0.631 \pm 0.202$ \\
\hline Increment 2-5 & $1.111 \pm 0.063$ & $1.079 \pm 0.083$ & $1.366 \pm 0.177$ & $1.498 \pm 0.145$ & $1.309 \pm 0.184$ & $1.018 \pm 0.169$ \\
\hline Increment 3-6 & $0.936 \pm 0.057$ & $0.828 \pm 0.068$ & $0.929 \pm 0.083$ & $1.080 \pm 0.156$ & $1.176 \pm 0.222$ & $1.034 \pm 0.178$ \\
\hline Increment 4-7 & $0.597 \pm 0.141$ & $0.500 \pm 0.014$ & $0.586 \pm 0.131$ & $0.600 \pm 0.144$ & $0.621 \pm 0.109$ & $0.570 \pm 0.096$ \\
\hline Increment 5-8 & $0.318 \pm 0.087$ & $0.208 \pm 0.069$ & $0.366 \pm 0.052$ & $0.301 \pm 0.057$ & $0.416 \pm 0.100$ & $0.367 \pm 0.073$ \\
\hline Global increment & $0.859 \pm 0.105$ & $0.786 \pm 0.115$ & $0.974 \pm 0.157$ & $1.057 \pm 0.168$ & $1.015 \pm 0.136$ & $0.831 \pm 0.103$ \\
\hline \multicolumn{7}{|c|}{$\mathrm{Fe}$} \\
\hline \multirow[t]{2}{*}{ Step $^{a}$} & \multicolumn{2}{|c|}{ Sample B } & \multicolumn{2}{|c|}{ Sample C } & \multicolumn{2}{|c|}{ Sample D } \\
\hline & Condition 1 & Condition 2 & Condition 1 & Condition 2 & Condition 1 & Condition 2 \\
\hline Increment 1-4 & $0.482 \pm 0.059$ & $0.605 \pm 0.115$ & $0.793 \pm 0.111$ & $0.773 \pm 0.089$ & $1.601 \pm 0.615$ & $1.329 \pm 0.507$ \\
\hline Increment 2-5 & $0.501 \pm 0.074$ & $0.654 \pm 0.139$ & $0.794 \pm 0.160$ & $0.688 \pm 0.166$ & $1.999 \pm 0.678$ & $1.724 \pm 0.526$ \\
\hline Increment 3-6 & $0.471 \pm 0.065$ & $0.407 \pm 0.079$ & $0.458 \pm 0.134$ & $0.463 \pm 0.063$ & $0.748 \pm 0.099$ & $0.638 \pm 0.121$ \\
\hline Increment 4-7 & $0.414 \pm 0.077$ & $0.235 \pm 0.038$ & $0.190 \pm 0.027$ & $0.418 \pm 0.058$ & $0.458 \pm 0.086$ & $0.459 \pm 0.024$ \\
\hline Increment 5-8 & $0.355 \pm 0.087$ & $0.194 \pm 0.044$ & $0.155 \pm 0.020$ & $0.398 \pm 0.069$ & $0.311 \pm 0.097$ & $0.544 \pm 0.066$ \\
\hline Global increment & $0.473 \pm 0.043$ & $0.465 \pm 0.086$ & $0.515 \pm 0.114$ & $0.573 \pm 0.077$ & $1.242 \pm 0.368$ & $1.090 \pm 0.291$ \\
\hline
\end{tabular}




\begin{tabular}{|c|c|c|c|c|c|c|}
\hline \multicolumn{7}{|c|}{$\mathrm{Cr}$} \\
\hline \multirow{2}{*}{ Step ${ }^{a}$} & \multicolumn{2}{|c|}{ Sample B } & \multicolumn{2}{|c|}{ Sample C } & \multicolumn{2}{|c|}{ Sample D } \\
\hline & Condition 1 & Condition 2 & Condition 1 & Condition 2 & Condition 1 & Condition 2 \\
\hline Increment 1-4 & $-\mathrm{b}$ & $2.690 \pm 0.850$ & $-b$ & $1.868 \pm 0.709$ & $1.590 \pm 0.335$ & $1.293 \pm 0.045$ \\
\hline Increment 2-5 & $-\mathrm{b}$ & $2.466 \pm 1.250$ & $-{ }^{b}$ & $-b$ & $1.733 \pm 0.405$ & $1.014 \pm 0.088$ \\
\hline Increment 3-6 & $-\mathrm{b}$ & $0.189 \pm 0.040$ & $1.234 \pm 0.759$ & $-b$ & $0.924 \pm 0.103$ & $0.806 \pm 0.078$ \\
\hline Increment 4-7 & $0.159 \pm 0.087$ & $0.371 \pm 0.074$ & $2.109 \pm 0.603$ & $0.721 \pm 0.396$ & $0.607 \pm 0.083$ & $0.558 \pm 0.069$ \\
\hline Increment 5-8 & $0.969 \pm 0.427$ & $0.568 \pm 0.100$ & $2.406 \pm 0.533$ & $1.168 \pm 0.277$ & $0.502 \pm 0.590$ & $0.472 \pm 0.040$ \\
\hline Global increment & $0.077 \pm 0.043$ & $1.369 \pm 0.600$ & $1.190 \pm 0.387$ & $0.350 \pm 0.196$ & $1.181 \pm 0.246$ & $0.797 \pm 0.087$ \\
\hline \multicolumn{7}{|c|}{$Z n$} \\
\hline \multirow[t]{2}{*}{ Step ${ }^{a}$} & \multicolumn{2}{|c|}{ Sample B } & \multicolumn{2}{|c|}{ Sample C } & \multicolumn{2}{|c|}{ Sample D } \\
\hline & Condition 1 & Condition 2 & Condition 1 & Condition 2 & Condition 1 & Condition 2 \\
\hline Increment 1-4 & $0.879 \pm 0.152$ & $1.136 \pm 0.155$ & $1.109 \pm 0.103$ & $1.095 \pm 0.085$ & $1.288 \pm 0.082$ & $1.265 \pm 0.111$ \\
\hline Increment 2-5 & $0.437 \pm 0.041$ & $0.606 \pm 0.132$ & $0.706 \pm 0.148$ & $0.907 \pm 0.164$ & $0.851 \pm 0.144$ & $0.793 \pm 0.106$ \\
\hline Increment 3-6 & $0.482 \pm 0.073$ & $0.581 \pm 0.141$ & $0.565 \pm 0.165$ & $0.781 \pm 0.180$ & $0.538 \pm 0.173$ & $0.535 \pm 0.068$ \\
\hline Increment 4-7 & $0.411 \pm 0.096$ & $0.299 \pm 0.087$ & $0.274 \pm 0.040$ & $0.446 \pm 0.059$ & $0.283 \pm 0.023$ & $0.352 \pm 0.045$ \\
\hline Increment 5-8 & $0.259 \pm 0.116$ & $0.354 \pm 0.096$ & $0.293 \pm 0.082$ & $0.352 \pm 0.092$ & $0.359 \pm 0.054$ & $0.253 \pm 0.021$ \\
\hline Global increment & $0.436 \pm 0.040$ & $0.501 \pm 0.075$ & $0.532 \pm 0.086$ & $0.726 \pm 0.094$ & $0.589 \pm 0.102$ & $0.577 \pm 0.085$ \\
\hline
\end{tabular}

IIncrement 1-4: from 0.25 to 4 days; Increment 2-5: from 1 to 9 days; Increment 3-6: from 2.25 to 16 days; Increment 4-7: from 4 to 36 days; Increment 5-8: from 9 to 64 days; Global increment: from 1 to 36 days.

${ }^{b}$ no changes of concentration were observed, so the quantified slope was null. 


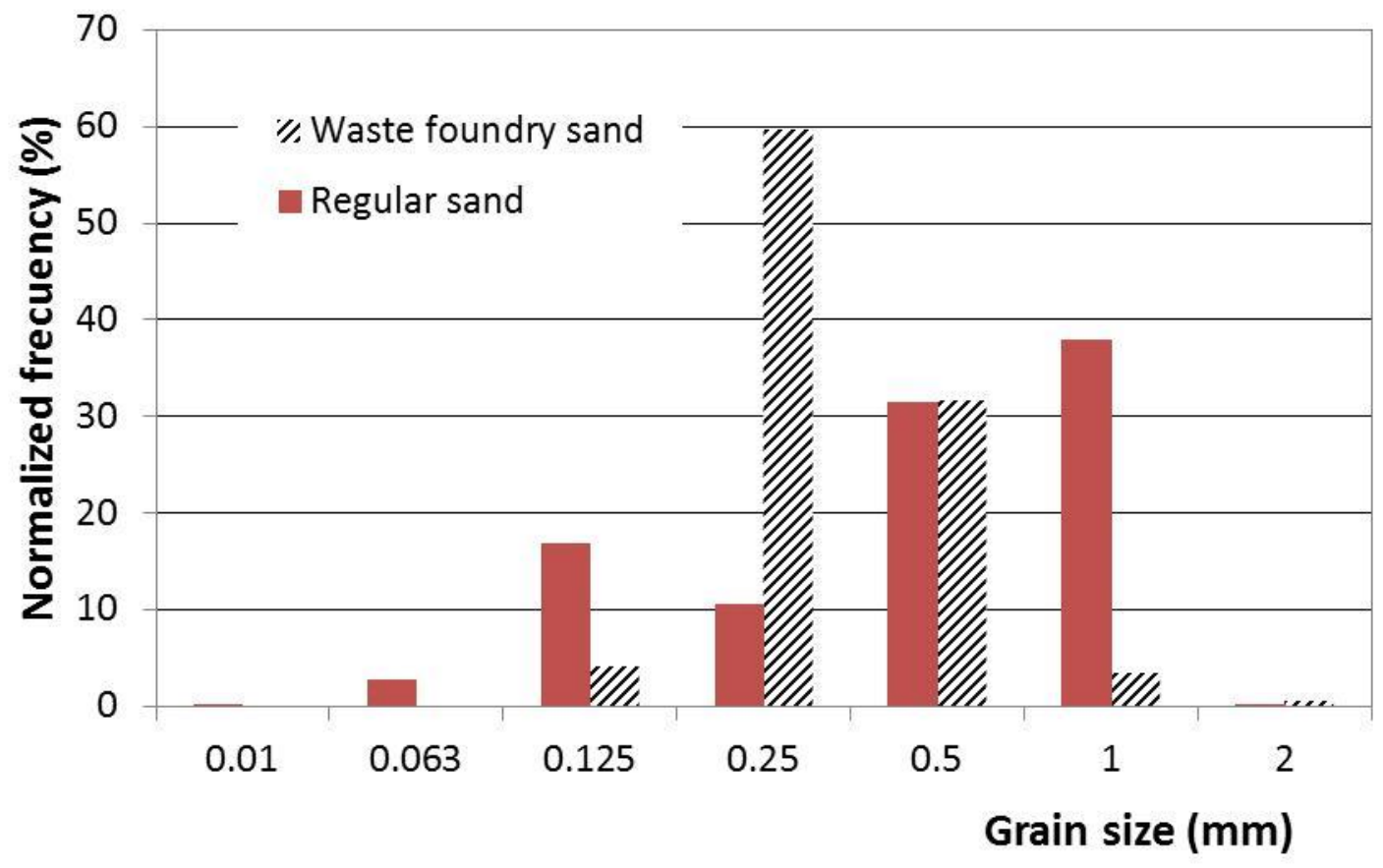

Figure 1. Particle size distribution of regular and waste foundry sands.

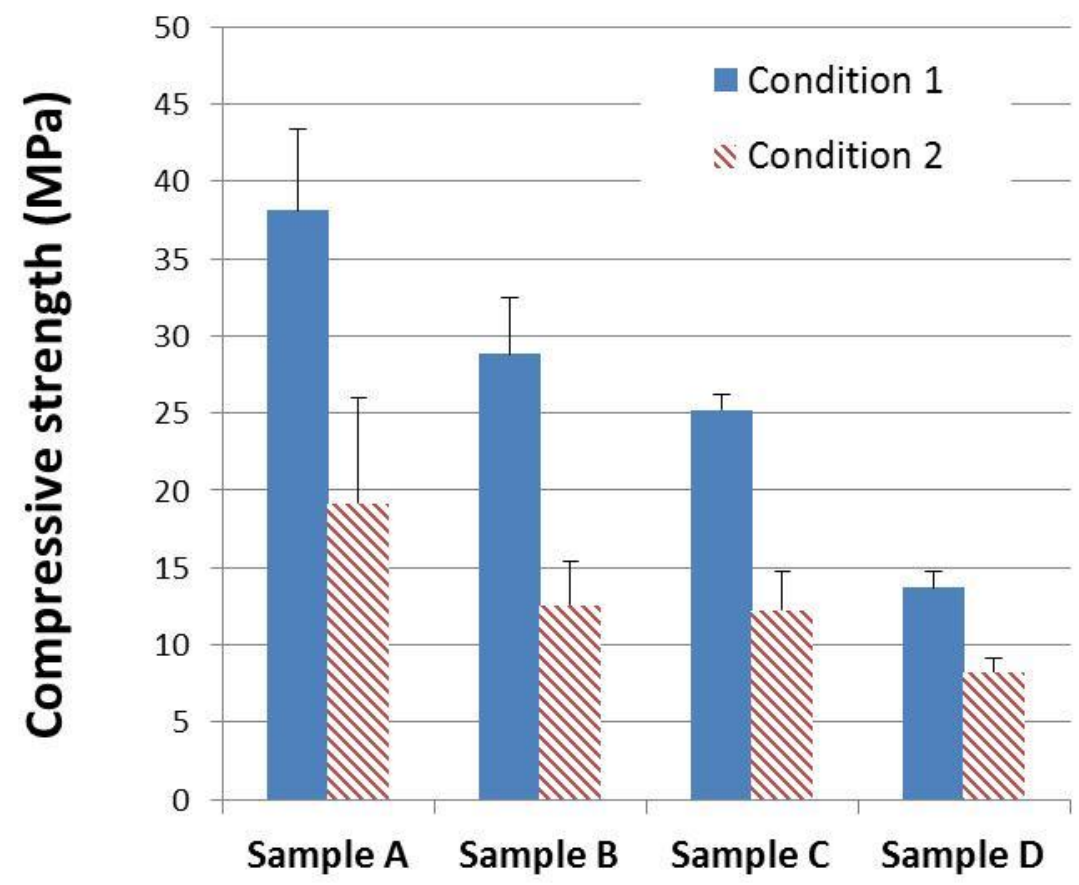

Figure 2. Compressive strengths for 28-day hardened specimens cured under condition $1\left(20^{\circ} \mathrm{C}, 95 \% \mathrm{RH}\right)$ and condition $2\left(60^{\circ} \mathrm{C}, 100 \% \mathrm{RH}\right)$. 


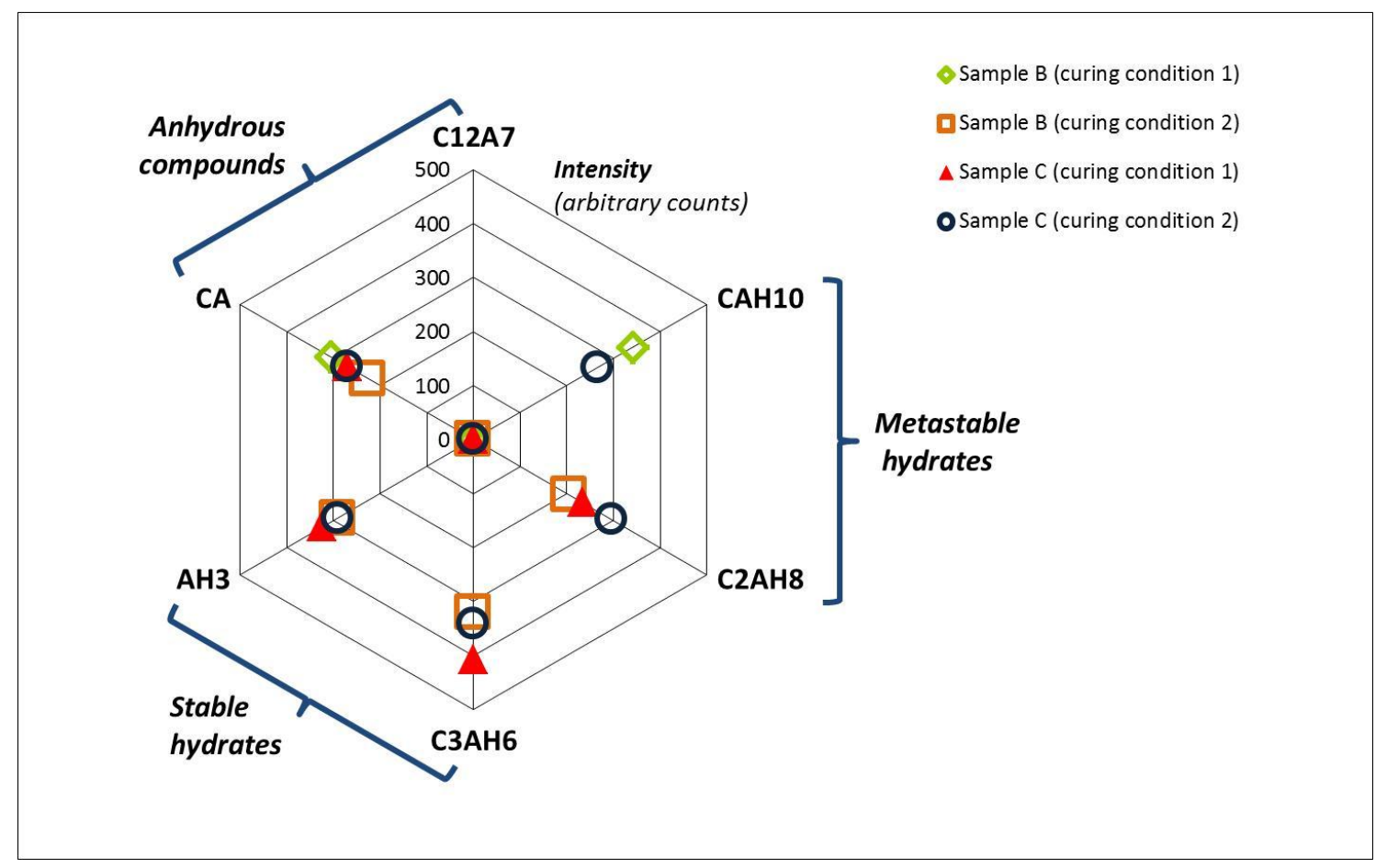

Figure 3. Relative abundance (intensity given in vertical axis in arbitrary units) of cementitious crystalline phases in samples B and C cured in either condition 1 or 2, as identified by XRD. 

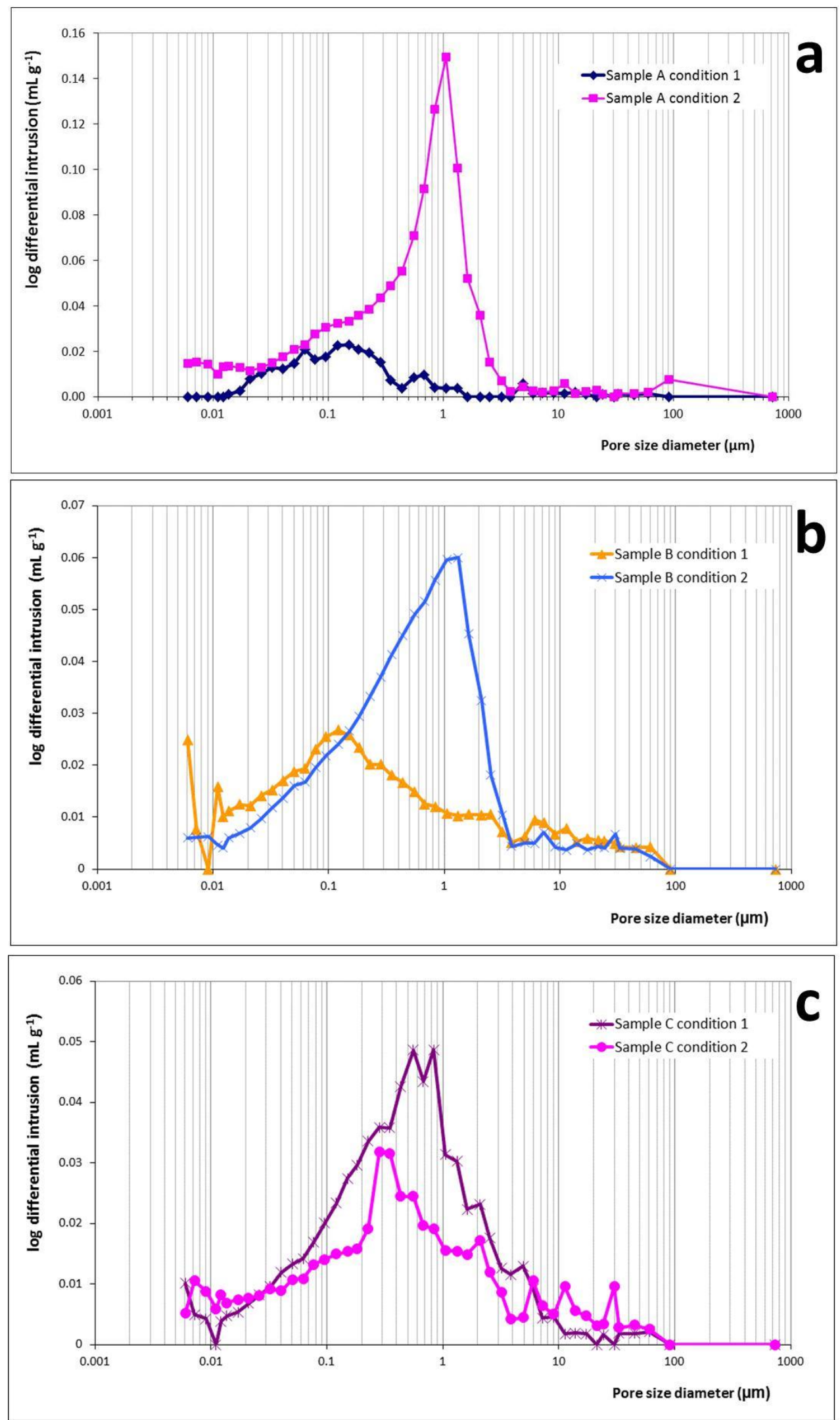

Figure 4. Pore size distribution of: a) samples B; b) samples C and c) samples D subjected to curing conditions 1 and 2. 


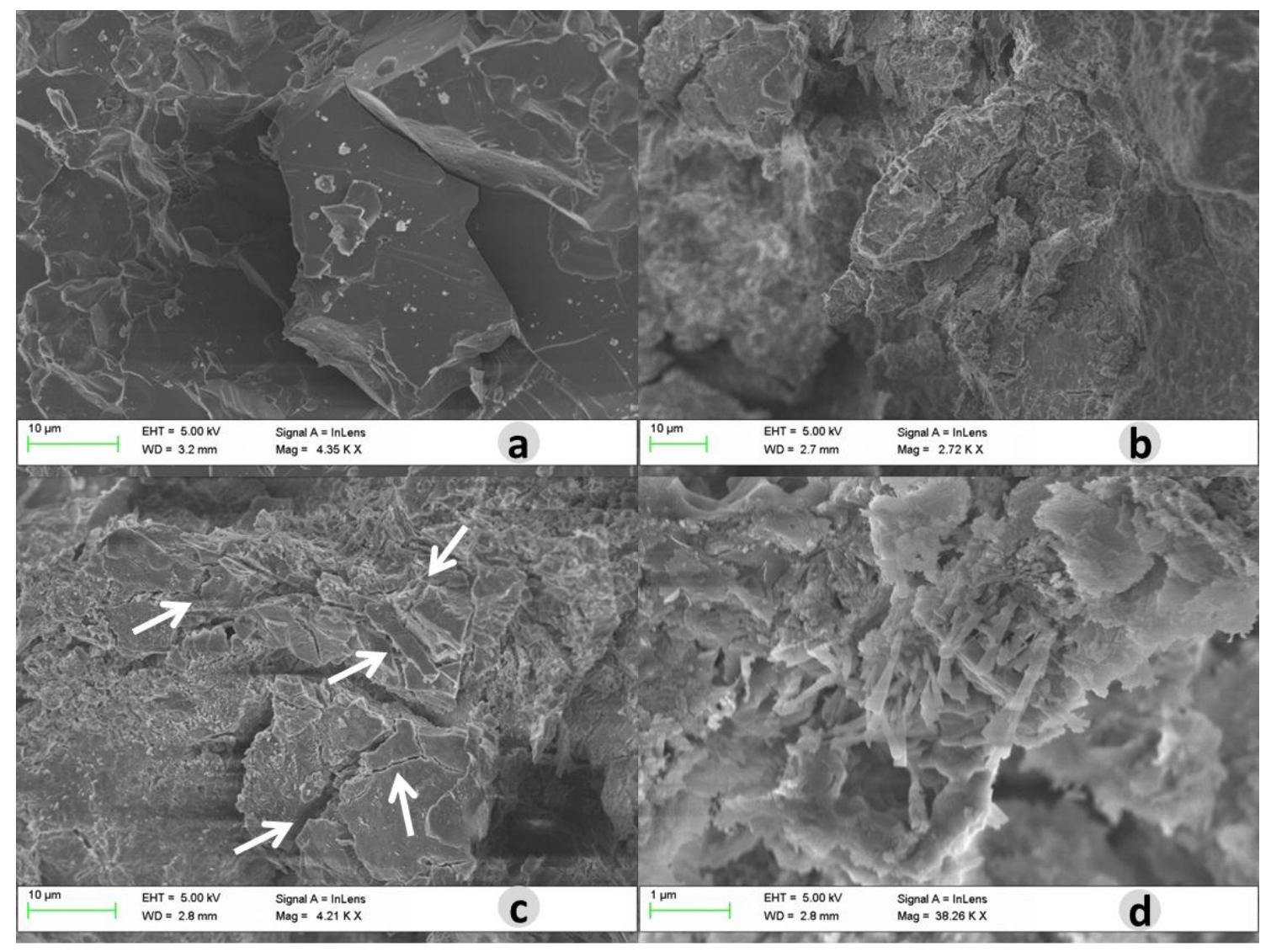

Figure 5. SEM micrographs of samples B after curing condition 1: a) gel-like structure of metastable hydrates, b) and c) microstructure showing cracks over the surface (indicated by arrows); d) ill-defined structure with rods and plate-like crystals. 


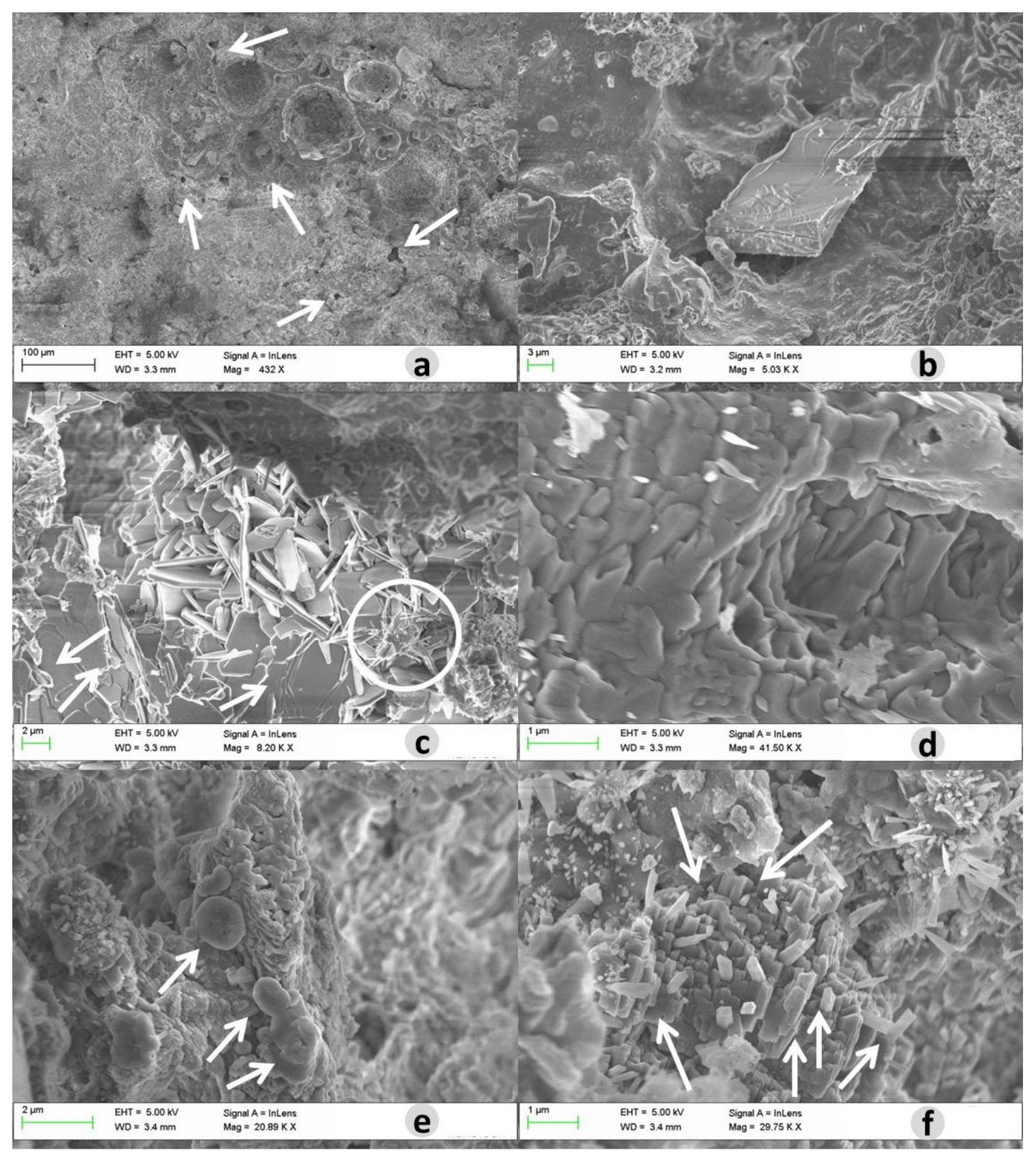

Figure 6. SEM analysis of samples B after curing condition 2: a) porous microstructure (some pores indicated by arrows), b) gel-like structure; c) tabular (arrows) and needle-like (encircled area) gibbsite crystals together with hexagonal plate-like metastable hydrates; d) tabular crystals agglomeration; e) spherical agglomerates of AH3 (arrows); f) prismatic (arrows) and tabular clusters of stable hydrates. 


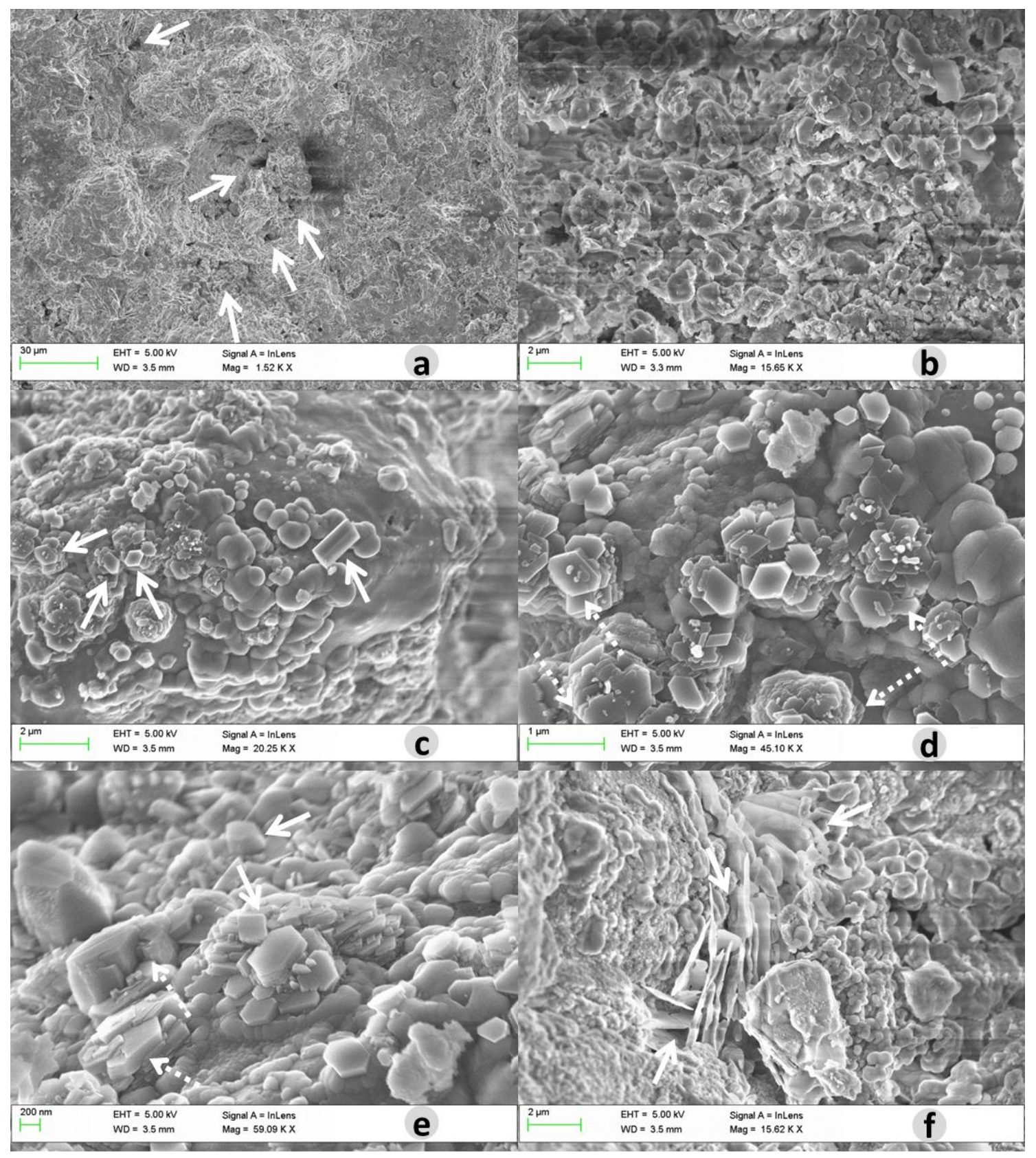

Figure 7. SEM examination of samples $\mathrm{C}$ (containing $\mathrm{CMCH}$ ) after curing condition 1: a) matrix with a low degree of homogeneity; b) ill-defined structure with quasi spherical $\mathrm{AH}_{3}$ crystals; c), d) and e) cubic and prismatic $\mathrm{C}_{3} \mathrm{AH}_{6}$ crystals (solid arrows) and spherical $\mathrm{AH}_{3}$ crystals. Hexagonally-shaped pinacoids of $\mathrm{C}_{2} \mathrm{AH}_{8}$ (dotted arrows); f) thin sheets of stable hydrates. 


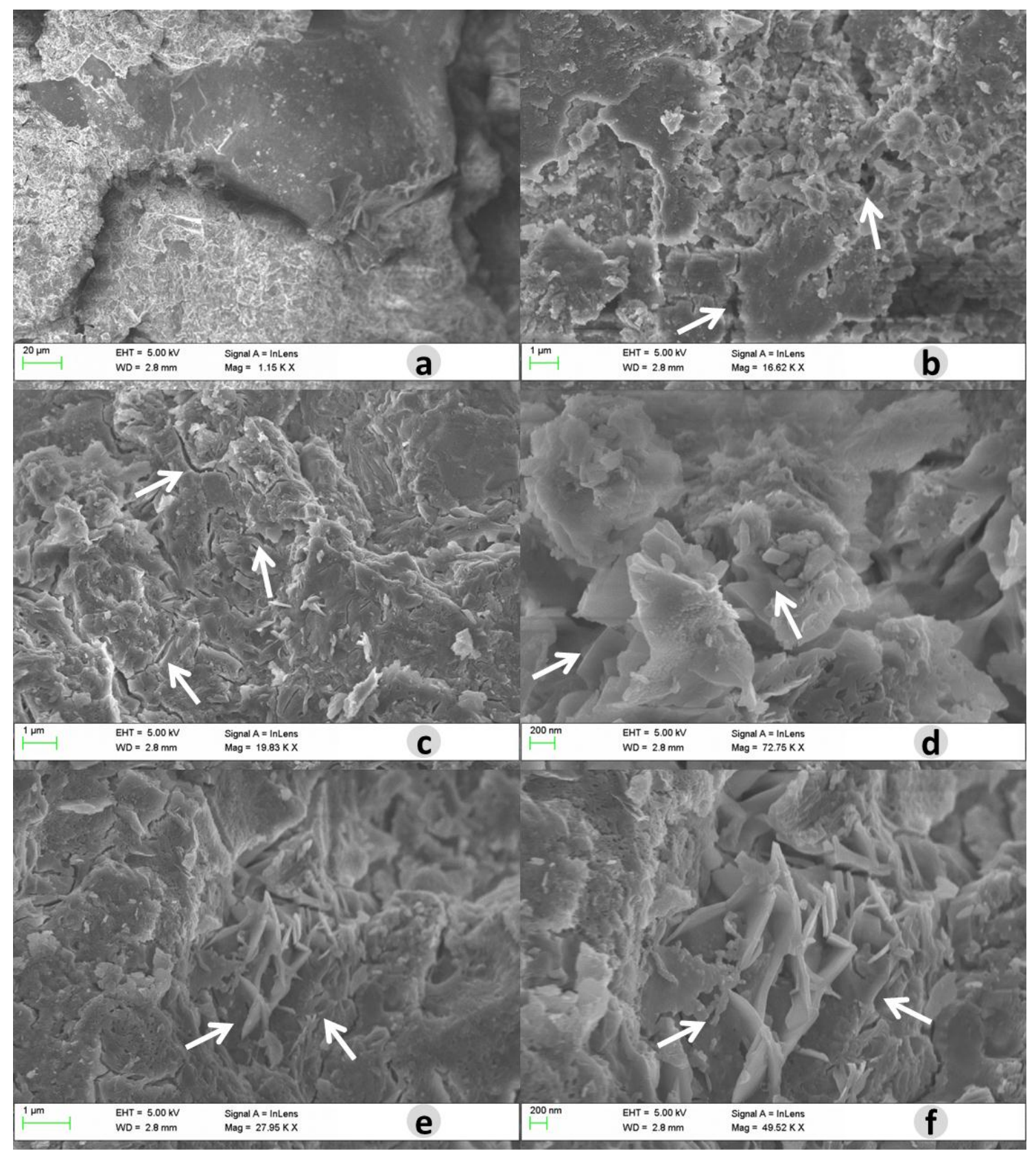

Figure 8. SEM micrographs of the microstructure of samples $C$ (chitosan-bearing CAC mortars) cured under condition 2: a) porous matrix; b) and c) gel-like structure with cracks (arrows); d) poorly crystallized matrix with some cubic crystals (arrows); e) and f) foil-like morphology.. 


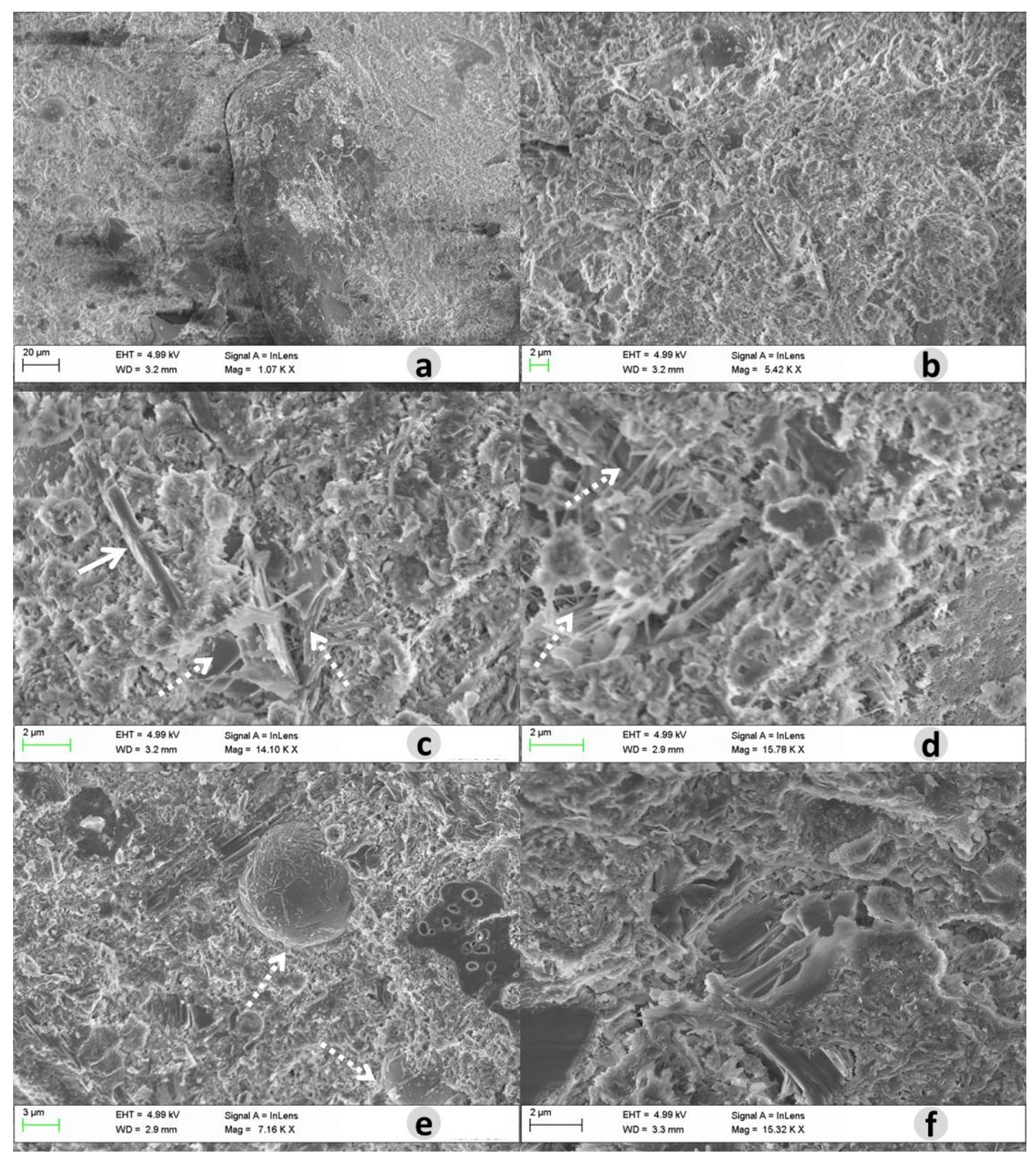

Figure 9. SEM images of OPC specimens (samples D) after curing at condition 1: a) and b) compact matrix; c) and d) fibrous C-S-H compounds (solid arrows) and needle-like ettringite crystals (dotted arrows); e) spherical particles attributed to fly ashes. In sample after condition 2 of curing (f) the matrix showed an irregular microstructure. 


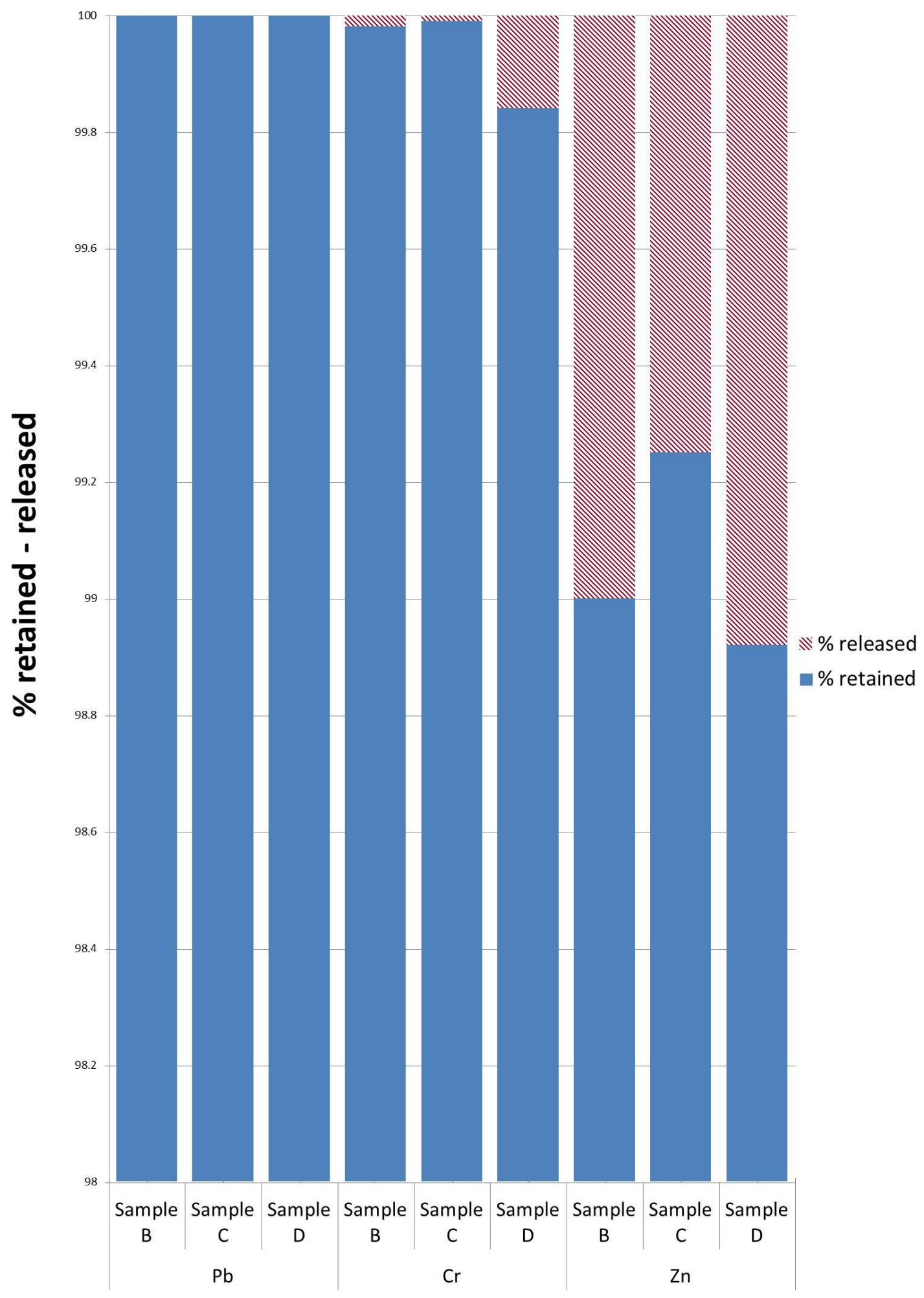

Figure 10. Percentages of metals retained and released from the 28-day hardened monolithic samples containing 50 wt.\% WFS (CAC: samples B and C; OPC: samples D). 


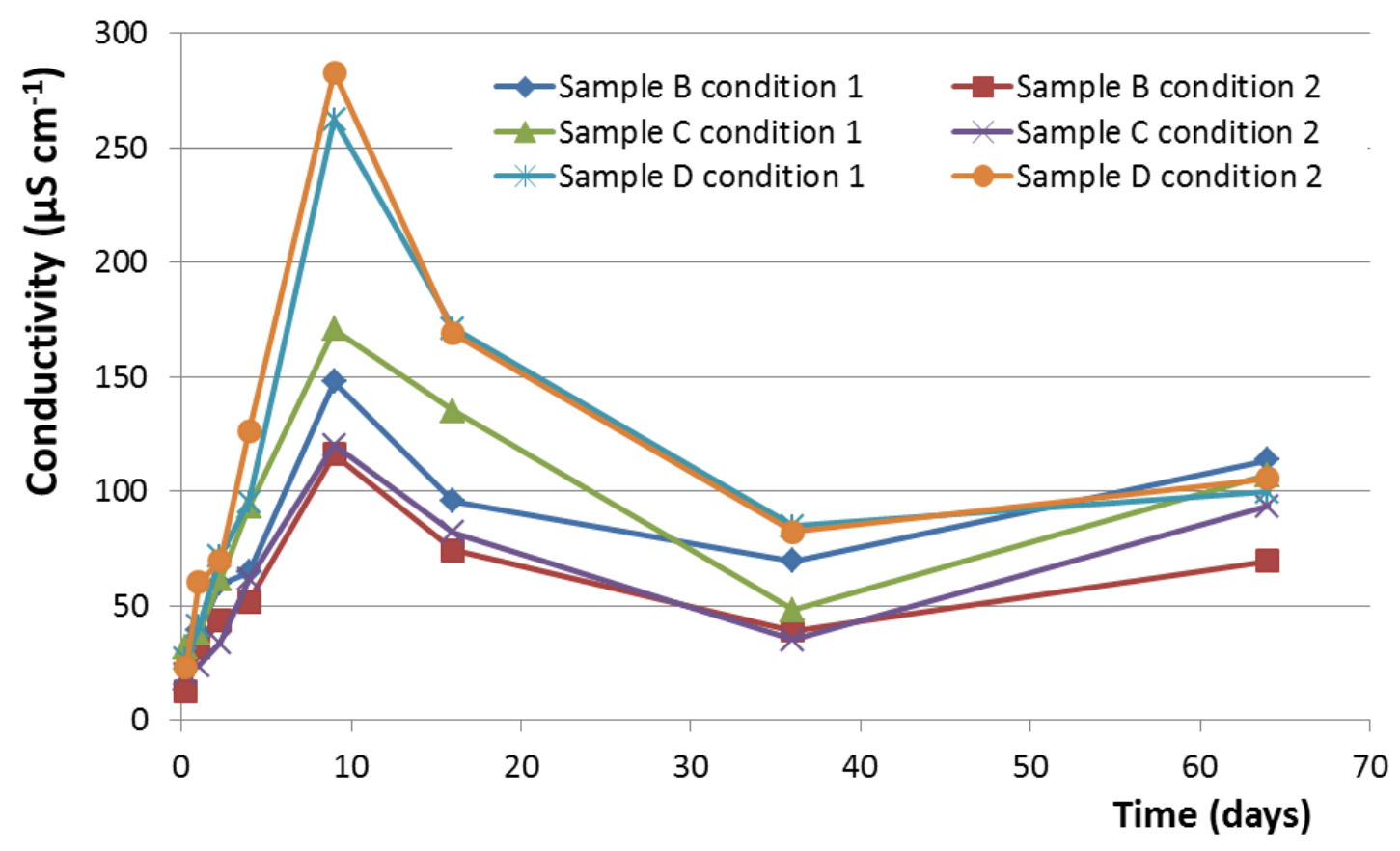

Figure 11. Conductivity of the eluates from samples B, C and D cured under both conditions (1 and 2). 